\title{
Oral Glucose Tolerance and Tryptophan Metabolism in Non-Obese and Non-Insulin-Dependent Diabetic Goto-Kakizaki Rats Fed High-Tryptophan Diets
}

\author{
Eri IMAI ${ }^{1}$ and Katsumi SHIBATA ${ }^{2, *}$ \\ ${ }^{1}$ Department of Nutrition, School of Human Cultures, The University of Shiga Prefecture, \\ Hikone, Shiga 522-8533, Japan \\ ${ }^{2}$ Department of Physical Therapy, Faculty of Nursing and Rehabilitation, \\ Konan Women's University, Higashinada-ku, Kobe 658-0001, Japan
}

(Received August 2, 2017)

\begin{abstract}
Summary We investigated oral glucose tolerance and tryptophan (Trp) metabolism in non-obese and non-insulin-dependent diabetic Goto-Kakizaki (GK) rats fed high-Trp diets. Five-week-old male Wistar and GK rats were fed a 20\% casein diet (control diet) or the same diet supplemented with $1 \%, 2 \%, 3 \%$, or $5 \% \operatorname{Trp}$ for $58 \mathrm{~d}$. Oral glucose tolerance tests were performed on Days 14 and 28 of the experimental period. Urine as well as livers and blood were collected on the last day of the experiment. The glucose concentration and the amount of Trp metabolites were measured. On Day 14 of the experiment, the incremental blood glucose concentrations integrated over a period of $2 \mathrm{~h}\left(\Delta \mathrm{AUC}_{0-2 \mathrm{~h}}\right)$ of blood glucose in rats fed the $3 \%$ and $5 \%$ Trp diets had decreased by $13 \%$ and $18 \%$, respectively, compared with that of the control-GK rats. However, no significant differences were found in the rats fed $+1 \%$ or $+2 \%$ Trp diets compared with control-GK rats. On Day 28 , there were no significant differences found in the $\Delta \mathrm{AUC}_{0-2 \mathrm{~h}}$ of blood glucose levels in any group including the control-GK group. On the last day, the concentrations of plasma glucose, total cholesterol, and triglyceride did not show differences in any group. There were no specific phenomena observed in the metabolism of Trp in GK rats even when fed an excess of Trp, compared with that of Wistar rats. Oral Trp administration and its continuous use may not improve blood glucose levels in type 2 diabetic rats.
\end{abstract}

Key Words GK rat, tryptophan metabolism, glucose tolerance, diabetes, excessive tryptophan

Nicotinamide (Nam), serotonin, and melatonin are important bioactive compounds derived from the essential amino acid, tryptophan (Trp) (1-3). Several studies have demonstrated that Trp can regulate physiological processes and may be the basis for novel therapeutics to prevent or treat chronic diseases (4).

Previously, it was shown that plasma Trp levels in diabetic rats and children with insulin-dependent diabetes were significantly lower than normal (5-7). Recently, metabolome analysis demonstrated that plasma concentrations of Trp and its metabolite kynurenine were lower in type 2 diabetic Torii rats than in normal rats (7). It is known that Trp deficiency modulates glucose tolerance (8). Lower concentrations of Trp in blood lead to lower concentrations of serotonin, which could contribute to depression in diabetes (6).

Data on Trp intake and blood glucose concentrations in diabetic conditions are limited. In the two reports published, oral administration of Trp did not modify glycemia in type 2 diabetic rats (9) and oral administration of Trp suppressed the elevation of blood glucose concentration in type 2 diabetic rats when the

\footnotetext{
*To whom correspondence should be addressed.

E-mail: kshibata@konan-wu.ac.jp
}

rats were glucose-loaded (10). Based on these results, we hypothesized that a single intravenous injection of Trp suppresses blood glucose concentration, whereas oral intake of Trp over several days will not influence glucose concentration in diabetic rats. Previously, we demonstrated that the Trp-Nam conversion ratio was significantly lower in streptozotocin-induced type 1 diabetic rats than in healthy control rats (11); however, the activity of Trp 2,3-dioxygenase was accelerated by diabetic conditions (12). In addition, the catabolism of Nam in these groups of rats was not similar (11). These results suggest that the Trp requirement is higher in diabetic conditions than in normal conditions.

To the best of our knowledge, no previous studies have investigated the effect of continuous intake of Trp on blood glucose concentrations in type 2 diabetic rats. Therefore, we investigated oral glucose tolerance and Trp metabolism in non-obese and non-insulin-dependent diabetic Goto-Kakizaki (GK) (an animal model of type 2 diabetes) rats fed high-Trp diets.

\section{MATERIALS AND METHODS}

Chemicals. Vitamin-free milk casein, sucrose, L-methionine, gelatinized cornstarch, Trp, Nam, anthranilic acid (AnA) and quinolinic acid (QA) were 
purchased from Wako Pure Chemical Industries, Ltd. (Osaka, Japan). Kynurenic acid (KA), xanthurenic acid (XA), 3-hydroxyanthranic acid (3-HA), and $N^{1}$-methylnicotinamide (MNA) chloride were purchased from Tokyo Chemical Industry Co., Ltd. (Tokyo, Japan). $N^{1}$-methyl-2-pyridone-5-carboxamide (2-Py) and $N^{1}$ methyl-4-pyridone-3-carboxamide (4-Py) were synthesized using the methods of Pullman and Colowick (13) and Shibata et al. (14) respectively. Corn oil was purchased from Ajinomoto Co., Inc. (Tokyo, Japan). The mineral mixture (AIN-93G-MX) (15) and nicotinic-acidfree vitamin mixture (AIN-93-VX) (15) were purchased from Oriental Yeast Co., Ltd. (Tokyo, Japan). All of the other chemicals used in this study were of the highest purity available from commercial sources.

Experimental animals and diets. Animals were maintained in a temperature-controlled room $\left(22^{\circ} \mathrm{C}\right)$ with $60 \%$ relative humidity and a 12 -h light/dark cycle (lights on: 06:00-18:00). Five-week-old male Wistar and GK rats weighing around $40 \mathrm{~g}$ were obtained from CLEA Japan, Inc. (Tokyo, Japan). The GK rat is a genetic animal model of type 2 diabetes that was created by selective breeding of an outbred colony of Wistar rats, with selection for high glucose levels in an oral glucose tolerance test (OGTT) (16). General characteristics of the GK rat include fasting hyperglycemia, impaired secretion of insulin in response to glucose both in vivo and in isolated pancreata, raised glycosylated hemoglobin, hepatic and peripheral insulin resistance and a variety of late complications, including nephropathy and neuropathy (16-18). The rats were divided into six groups of five rats each, and each group was placed in an individual metabolic cage (CT-10; CLEA Japan, Inc.). Rats in the control-Wistar and control-GK group were fed a $20 \%$ casein diet (containing $0.26 \%$ Trp) until the end of the experiment. The other groups were fed a $20 \%$ casein diet supplemented with $1 \%, 2 \%, 3 \%$, or $5 \%$ Trp. The rats were fed the diet and water ad libitum for $58 \mathrm{~d}$. The first day of the experiment was designated Day 1 . Body weights and food consumption were recorded daily around 09:00 am. On the last day (Day 58, 09:00 am-Day 59, 09:00 am), 24-h urine samples were collected in amber bottles containing $1 \mathrm{~mL}$ of $1 \mathrm{~mol} / \mathrm{L} \mathrm{HCl}$ and were stored at $-20^{\circ} \mathrm{C}$ until needed. After urine collection had been finished (Day 59, 09:00 am), the rats were sacrificed by decapitation, blood was collected in heparinized tubes, and livers were removed. The care and treatment of the experimental animals conformed to the University of Shiga Prefecture guidelines for the ethical treatment of laboratory animals (approval number, No. 21-4).

Measurements of Trp and its metabolites. Nam (19) and its catabolites, MNA (20), 2-Py, and 4-Py (19), in urine were measured directly by high-performance liquid chromatography (HPLC). To measure the total Nam (pyridine nucleotides + free type of Nam) content in the blood and liver, whole blood and liver homogenate were autoclaved at $121^{\circ} \mathrm{C}$ for $20 \mathrm{~min}$ to convert the pyridine nucleotides to Nam. The resulting Nam measurement was then determined by $\operatorname{HPLC}(14,19)$. The urinary concentration of 3-HA and XA was measured using the methods of Shibata and Onodera (21), the urinary concentration of KA was measured using the method of Shibata (22), and the urinary concentration of QA was measured using the method of Mawatari et al. (23).

Oral glucose tolerance test (OGTT). OGTT was performed on Days 14 and 28 during the experiment. Five rats were used in each group and fasted for 17-20 h before the experiments. For OGTT, $0.4 \mathrm{~mL}$ of $50 \%$ glucose solution per $100 \mathrm{~g}$ body weight $(2 \mathrm{~g}$ glucose $/ \mathrm{kg}$ body weight) was orally administered. Blood was collected through the tail artery immediately before ( $0 \mathrm{~min})$ and 30, 60, 90, and 120 min after glucose administration. Plasma glucose concentrations were measured using a glucose oxidase method with the help of a blood glucose meter (Glutest Every; Sanwa-Kagaku, Nagoya, Japan). Glucose concentrations were calculated as the incremental blood glucose concentrations integrated over a period of $2 \mathrm{~h}\left(\Delta \mathrm{AUC}_{0-2 \mathrm{~h}}\right)$ after glucose loading.

General biomarkers in blood and urine. Glucose, total cholesterol, triglycerides, albumin, and urea nitrogen in plasma samples were measured using a FUJI DRI-CHEM 3500V (Fujifilm Medical Co., Ltd., Tokyo Japan). Plasma and urine creatinine were measured using a colorimetric method (24).

Statistical analysis. All experimental data are expressed as means with the standard error of the mean for each group. The statistical significance was determined by one-way analysis of variance (ANOVA), followed Tukey's test or a two-way ANOVA to evaluate the effect of Trp diet group and OGTT performance day (Day 14 and Day 28), followed by Bonferroni's post hoc test. Body weights, food intake, clinical parameters, organ weights, and Nam and its metabolites were compared between control-Wistar, control-GK rats and rats with different concentrations of Trp intake. The area under the curve $(\mathrm{AUC})$ was calculated using the trapezoidal rule. Differences at $p<0.05$ were considered statistically significant. Prism 4.0 (Graph Pad Software, San Diego, CA) was used for all analyses.

\section{RESULTS}

Effects of Trp intake on body weight, food intake, and organ weights of GK rats

Table 1 shows the body weight, food intake, and organ weights of Wistar and GK rats. The total food intakes during the experiment in the control-Wistar group were higher than in the GK groups, and the intakes of the control-GK, $+1 \%$ Trp, and $+2 \%$ Trp diet groups were the same. Meanwhile, they were lower in the $+3 \%$ Trp and $+5 \%$ Trp diet groups compared with those of the control-GK, $+1 \%$ Trp and $+2 \%$ Trp diet groups.

The body weight gains during the experiment in the control-Wistar group were higher than in the GK groups, and these were the same among the controlGK and $+1 \%$ Trp diet groups. They were lower in the groups fed the $+2 \%$ Trp, $+3 \%$ Trp, and $+5 \%$ Trp diets compared with those of the control-GK and $+1 \%$ Trp diet groups.

Liver weights were lower in the $+5 \%$ Trp diet group 
Table 1. Effects of Trp intake on body weight, food intake, urine volume, organ weights and clinical parameters in GK rats.

\begin{tabular}{|c|c|c|c|c|c|c|}
\hline & Control-Wistar & $\begin{array}{l}\text { Control-GK } \\
(+0 \% \text { Trp })\end{array}$ & $+1 \% \operatorname{Trp}$ & $+2 \% \operatorname{Trp}$ & $+3 \% \operatorname{Trp}$ & $+5 \% \operatorname{Trp}$ \\
\hline Initial body weight (g) & $112.7 \pm 0.7$ & $92.2 \pm 4.1$ & $92.4 \pm 4.0$ & $92.9 \pm 4.2$ & $92.7 \pm 4.3$ & $92.9 \pm 4.9$ \\
\hline Final body weight (g) & $419.6 \pm 11.1^{\mathrm{a}}$ & $330.1 \pm 4.1^{\mathrm{b}}$ & $308.4 \pm 7.0^{\mathrm{c}}$ & $299.4 \pm 2.1^{\mathrm{c}}$ & $297.7 \pm 3.6^{c}$ & $274.8 \pm 5.7^{\mathrm{d}}$ \\
\hline Body weight gain (g) & $306.8 \pm 11.4^{\mathrm{a}}$ & $237.8 \pm 3.0^{\mathrm{b}}$ & $215.9 \pm 10.1^{\mathrm{b}}$ & $206.5 \pm 4.6^{c}$ & $205.0 \pm 3.6^{\mathrm{cd}}$ & $181.9 \pm 4.5^{\mathrm{d}}$ \\
\hline Total food intake (g/58 d) & $1,059.1 \pm 15.3^{\mathrm{a}}$ & $880.5 \pm 12.9^{\mathrm{b}}$ & $849.3 \pm 9.3^{b}$ & $841.5 \pm 25.2^{\mathrm{b}}$ & $797.5 \pm 19.8^{\mathrm{c}}$ & $743.1 \pm 10.7^{\mathrm{c}}$ \\
\hline Trp intake $(\mu \mathrm{mol} / \mathrm{d})$ & $253 \pm 4^{\mathrm{a}}$ & $209 \pm 3^{a}$ & $1,127 \pm 13^{b}$ & $1,876 \pm 53^{c}$ & $2,513 \pm 70^{\mathrm{d}}$ & $3,710 \pm 68^{\mathrm{e}}$ \\
\hline \multicolumn{7}{|l|}{ Organ weights } \\
\hline Liver $(\mathrm{g})$ & $14.5 \pm 0.7^{\mathrm{a}}$ & $12.3 \pm 0.4^{\mathrm{b}}$ & $12.1 \pm 0.3^{\mathrm{b}}$ & $11.8 \pm 0.4^{\mathrm{b}}$ & $10.9 \pm 0.3^{b}$ & $9.9 \pm 0.5^{c}$ \\
\hline Kidney (g) & $2.55 \pm 0.12$ & $2.65 \pm 0.12$ & $2.65 \pm 0.03$ & $2.59 \pm 0.07$ & $2.57 \pm 0.09$ & $2.57 \pm 0.07$ \\
\hline \multicolumn{7}{|l|}{ Clinical parameters } \\
\hline Plasma glucose (mg/dL) & $89 \pm 7^{\mathrm{a}}$ & $205 \pm 8^{b}$ & $167 \pm 23^{b}$ & $174 \pm 33^{\mathrm{b}}$ & $207 \pm 15^{b}$ & $212 \pm 17^{b}$ \\
\hline $\begin{array}{l}\text { Plasma total cholesterol } \\
\quad(\mathrm{mmol} / \mathrm{L})\end{array}$ & $2.83 \pm 0.08^{\mathrm{b}}$ & $4.01 \pm 0.04^{\mathrm{a}}$ & $3.51 \pm 0.35^{\mathrm{ab}}$ & $3.67 \pm 0.11^{\mathrm{a}}$ & $3.35 \pm 0.04^{\mathrm{ab}}$ & $3.19 \pm 0.07^{\mathrm{b}}$ \\
\hline Plasma triglyceride $(\mathrm{mmol} / \mathrm{L})$ & $2.42 \pm 0.31^{\mathrm{c}}$ & $1.26 \pm 0.14^{\mathrm{b}}$ & $1.26 \pm 0.12^{\mathrm{bc}}$ & $1.27 \pm 0.11^{\mathrm{ab}}$ & $1.12 \pm 0.12^{\mathrm{bc}}$ & $1.15 \pm 0.09^{\mathrm{ac}}$ \\
\hline Plasma creatinine $(\mathrm{mmol} / \mathrm{L})$ & $0.02 \pm 0.00$ & $0.01 \pm 0.00$ & $0.01 \pm 0.00$ & $0.01 \pm 0.00$ & $0.01 \pm 0.00$ & $0.02 \pm 0.00$ \\
\hline Plasma albumin (mmol/L) & $0.66 \pm 0.31$ & $0.71 \pm 0.01$ & $0.69 \pm 0.01$ & $0.69 \pm 0.01$ & $0.67 \pm 0.01$ & $0.68 \pm 0.01$ \\
\hline $\begin{array}{l}\text { Plasma urea nitrogen } \\
(\mathrm{mmol} / \mathrm{L})\end{array}$ & $20.9 \pm 0.6$ & $17.8 \pm 1.0$ & $20.4 \pm 1.0$ & $22.1 \pm 1.8$ & $18.6 \pm 1.2$ & $18.1 \pm 1.3$ \\
\hline Urine creatinine (mg/d) & $4.3 \pm 0.1^{\mathrm{a}}$ & $15.0 \pm 1.3^{\mathrm{bc}}$ & $15.7 \pm 2.1^{\mathrm{bc}}$ & $18.0 \pm 2.4^{\mathrm{b}}$ & $14.7 \pm 0.9^{\mathrm{bc}}$ & $10.9 \pm 1.0^{c}$ \\
\hline
\end{tabular}

Trp, tryptophan.

Data are presented as mean \pm SE for five rats.

Mean values within a row with unlike superscript letters are significantly different as determined by one-way analysis of variance with Tukey's multiple comparison test $(p<0.05)$.

${ }^{1}$ Trp intake: food intake $(\mathrm{g} / \mathrm{d}) \times 0.2 \times 0.875 \times 0.013 \times 1 / 204 \times 10^{6}$
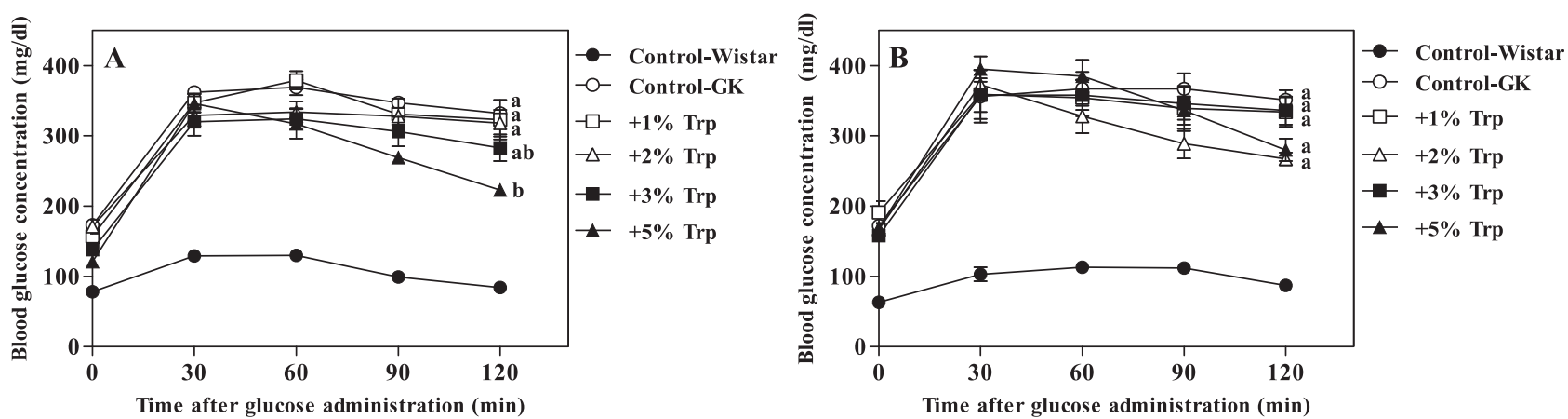

Fig. 1. Oral glucose tolerance test (OGTT) in Wistar and GK rats. OGTT was performed on Days 14 (A) and 28 (B) of the experiment. GK rats were fasted for 17-20 h before the OGTT. Mean values with unlike superscript letters were significantly different among GK-groups as determined by one-way analysis of variance with Tukey's multiple comparison test $(p<0.05)$.

than in the other diet groups. No differences in kidney weights were observed among the groups.

Effects of Trp intake on the clinical parameters of GK rats

Table 1 shows the clinical parameters in Wistar and GK rats. The plasma glucose concentrations on Day 58 (the last day of the experiment) in the control-Wistar group were higher than in the GK groups (Table 1). Meanwhile, no differences in the plasma glucose concentrations on Day 58 were observed among any diet groups in GK-rats.

The plasma total cholesterol levels in the $+5 \% \operatorname{Trp}$ diet group was lower than in the control-GK group, although no differences in these values for the other Trp diet groups were observed compared with those of the
control-GK group. The plasma triglyceride concentration in the control-Wistar group was higher than in the control-GK group and $+2 \%$ Trp diet group. The plasma triglyceride concentration in the $+5 \%$ Trp diet group was lower than in the control-GK group, although no differences in this value for the other Trp diet groups were observed compared with that of the control-GK group. No differences in concentrations of plasma albumin and plasma urea nitrogen were observed among any diet groups. The urine creatinine concentration was lower in the $+5 \%$ Trp diet group than in the $+2 \%$ Trp diet groups.

Effects of Trp intake on blood glucose tolerance of GK rats

To estimate the effect of Trp on blood glucose con- 
Table 2. Effects of Trp intake on the fasting, 120-min blood glucose levels and $\Delta \mathrm{AUC}_{0-2 \mathrm{~h}}$ concentrations in GK rats on Day 14 and Day 28 of the experiment.

\begin{tabular}{|c|c|c|c|c|c|c|}
\hline \multirow{2}{*}{ Group } & \multicolumn{2}{|c|}{ Fasting blood glucose (mg/dL) } & \multicolumn{2}{|c|}{ 120-min blood glucose $(\mathrm{mg} / \mathrm{dL})$} & \multicolumn{2}{|c|}{$\Delta \mathrm{AUC}_{0-2 \mathrm{~h}}{ }^{1}(\mathrm{mg} / \mathrm{dL}$ per min $)$} \\
\hline & Day 14 & Day 28 & Day 14 & Day 28 & Day 14 & Day 28 \\
\hline Control-Wistar & $78 \pm 2$ & $63 \pm 3$ & $84 \pm 5$ & $87 \pm 6$ & $106 \pm 1$ & $103 \pm 2$ \\
\hline Control-GK (+0\% Trp) & $173 \pm 11^{\mathrm{a}}$ & $172 \pm 11$ & $332 \pm 8^{a}$ & $351 \pm 14^{\mathrm{a}}$ & $330 \pm 8^{a}$ & $336 \pm 17$ \\
\hline$+1.0 \% \operatorname{Trp}$ & $147 \pm 10^{\mathrm{a}}$ & $178 \pm 12$ & $323 \pm 28^{a}$ & $334 \pm 21^{\mathrm{ab}}$ & $318 \pm 15^{\mathrm{a}}$ & $327 \pm 22$ \\
\hline$+2.0 \% \operatorname{Trp}$ & $157 \pm 3^{\mathrm{ac}}$ & $167 \pm 9$ & $318 \pm 19^{a}$ & $267 \pm 9^{b}$ & $308 \pm 9^{a}$ & $297 \pm 17$ \\
\hline$+3.0 \% \operatorname{Trp}$ & $138 \pm 7^{\mathrm{ab}}$ & $158 \pm 6$ & $283 \pm 19^{\mathrm{ab}}$ & $299 \pm 17^{a b}$ & $288 \pm 10^{\mathrm{b}}$ & $321 \pm 18$ \\
\hline$+5.0 \% \operatorname{Trp}$ & $121 \pm 6^{\mathrm{b}}$ & $169 \pm 6$ & $223 \pm 7^{b}$ & $280 \pm 16^{\mathrm{b}}$ & $270 \pm 6^{\mathrm{b}}$ & $329 \pm 13^{*}$ \\
\hline \multicolumn{7}{|l|}{ One-way ANOVA ${ }^{2}$} \\
\hline Group effect & $p<0.05$ & NS & $p<0.05$ & $p<0.05$ & $p<0.05$ & NS \\
\hline \multicolumn{7}{|l|}{ Two-way ANOVA 3} \\
\hline Group effect & \multicolumn{2}{|c|}{$p<0.05$} & \multicolumn{2}{|c|}{$p<0.05$} & \multicolumn{2}{|c|}{ NS } \\
\hline Time effect & \multicolumn{2}{|c|}{$p<0.05$} & \multicolumn{2}{|c|}{ NS } & \multicolumn{2}{|c|}{$p<0.05$} \\
\hline $\begin{array}{r}\text { Interaction effect } \\
(\text { Group } \times \text { Time })\end{array}$ & \multicolumn{2}{|c|}{ NS } & \multicolumn{2}{|c|}{$p<0.05$} & \multicolumn{2}{|c|}{ NS } \\
\hline $\begin{array}{l}\text { Trp, tryptophan; AUC, area } \\
\text { Data are presented as mean } \\
{ }^{1} \Delta \mathrm{AUC}_{0-2 \mathrm{~h}} \text { increment blood } \\
{ }^{2} \text { Significance was determin } \\
\text { script letters are significant } \\
{ }^{3} \text { Significance was determin }\end{array}$ & $\begin{array}{l}\text { under the cu } \\
\pm \text { SE for five } \\
\text { d glucose con } \\
\text { aed by one-wa } \\
\text { tly different by } \\
\text { aed by two-wa }\end{array}$ & $\begin{array}{l}\text { NS, not signif } \\
\text { tration integrat } \\
\text { NOVA among } \\
\text { key's multiple } \\
\text { NOVA }(p<0.05\end{array}$ & $\begin{array}{l}\text { ed over a period } \\
\text { GK-rat groups, } \\
\text { comparison test } \\
\text { ) among GK-ra }\end{array}$ & $\begin{array}{l}2 \mathrm{~h} . \\
\text { mean values n } \\
0.05) \text {. } \\
\text { oups. }\end{array}$ & ithin a row wi & unlike super- \\
\hline
\end{tabular}

Table 3. Effects of Trp intake on the Nam concentration in blood and liver in GK rats.

\begin{tabular}{|c|c|c|c|c|c|c|}
\hline & Control-Wistar & $\begin{array}{l}\text { Control-GK } \\
(+0 \% \text { Trp) }\end{array}$ & $+1 \% \operatorname{Trp}$ & $+2 \% \operatorname{Trp}$ & $+3 \% \operatorname{Trp}$ & $+5 \% \operatorname{Trp}$ \\
\hline Blood total Nam $(\mu \mathrm{mol} / \mathrm{mL})$ & $135 \pm 4^{\mathrm{a}}$ & $101 \pm 3^{b}$ & $115 \pm 3^{\mathrm{d}}$ & $132 \pm 3^{\text {acd }}$ & $135 \pm 5^{\mathrm{acd}}$ & $152 \pm 8^{\mathrm{ac}}$ \\
\hline Liver Nam ( $\mu \mathrm{mol} / \mathrm{g}$ of liver $)$ & $1.96 \pm 0.06^{\mathrm{a}}$ & $2.00 \pm 0.05^{\mathrm{a}}$ & $3.24 \pm 0.13^{b}$ & $3.38 \pm 0.16^{b}$ & $3.24 \pm 0.23^{\mathrm{b}}$ & $3.00 \pm 0.09^{b}$ \\
\hline
\end{tabular}

Trp, tryptophan; Nam, nicotinamide.

Data are presented as mean \pm SE for five rats.

Mean values within a row with unlike superscript letters are significantly different from those of control-Wistar rats as determined by one-way ANOVA with Tukey's multiple comparison test $(p<0.05)$.

centrations, these were measured after glucose loading. Blood glucose reached the highest concentration (369 mg/dL) $1 \mathrm{~h}$ after glucose loading in the controlGK group (Fig. 1). On Day 14, the fasting and 120-min (after glucose loading) blood glucose concentrations were not significantly different between the controlGK group and the $+1 \%$ Trp, $+2 \%$ Trp or $+3 \%$ Trp diet groups, whereas in the $+5 \%$ Trp diet groups, they were significantly decreased compared with the control-GK and $+1 \%$ Trp diet group $(p<0.05)$. On Day 14 , the blood glucose concentration increased and finally reverted over a period of $2 \mathrm{~h}\left(\Delta \mathrm{AUC}_{0-2 \mathrm{~h}}\right.$ values) after the administration of glucose in the control-GK diet group, which was $330 \mathrm{mg} / \mathrm{dL} / \mathrm{min}$ (Table 2 ). The $+1 \%$ Trp and $+2 \%$ Trp diet did not affect the $\Delta \mathrm{AUC}_{0-2 \mathrm{~h}}$ of blood glucose on Day 14, whereas in the $+3 \% \operatorname{Trp}$ and $+5 \%$ Trp diet group, the $\Delta \mathrm{AUC}_{0-2 \mathrm{~h}}$ fell by $13 \%$ and $18 \%$, respectively, compared with the control-GK diet group $(p<0.05)$. On Day 28, no significant differences were observed among any of the groups with respect to increases in blood glucose concentrations. There was a significant time-effect change in fasting blood glucose and $\Delta \mathrm{AUC}_{0-2 \mathrm{~h}}$, but significant interaction was not observed (two-way ANOVA: time effect, $p<0.05$; interaction effect, NS). In a 120min blood glucose reading, the time-effect change had no significant difference, but significant interaction was observed (two-way ANOVA: time effect, NS; interaction effect, $p<0.05$ ). Multiple comparisons were made on a 120-min blood glucose result with interaction observed: the 120-min blood glucose level on Day 14 was significantly lower in the $+3 \%$ Trp diet than in the control-GK group, whereas the 120-min blood glucose readings on Day 28 in the $+2 \%$ and $+5 \%$ Trp diet were lower than in the control-GK group.

Effects of Trp intake on total Nam concentrations of blood and liver in GK rats

Table 3 shows the total Nam concentrations in the blood and liver. The total Nam concentrations in the 
blood were higher in the control-Wistar than in the control-GK group, and these concentrations in the $+2 \%$ Trp, $+3 \%$ Trp, and $+5 \%$ Trp diet groups were higher than in the control-GK group; however, there were no differences among the $+2 \% \operatorname{Trp},+3 \% \operatorname{Trp}$ and $+5 \% \operatorname{Trp}$ diet groups.

The Nam concentrations per gram of liver were also higher in the Trp diet groups than in the control-Wistar and control-GK group; however, there were no differences among the Trp diet groups.

Effects of Trp intake on the Trp-Nam pathway of GK rats

Table 4 shows the effects of Trp on the Trp-Nam metabolism. The relative Trp contents based on the diet composition in the control-GK, $+1 \%$ Trp, $+2 \%$ Trp, $+3 \%$ Trp, and $+5 \%$ Trp diet groups were 1.0, 4.8 . $8.7,12.5$, and 20.2 times, respectively. In comparison with the control-Wistar group, the control-GK group of excretion ratio of (2-Py+4-Py)/MNA was lower and the conversion ratio of Trp-Nam was higher. On the other hand, the other metabolites were essentially the same among the control-Wistar and control-GK groups. A particular phenomenon observed was that the urinary excretion amounts of Trp metabolites increased with Trp intake. Specifically, the urinary excretion of AnA dramatically increased in the $+5 \%$ Trp diet group. The urinary excretion amounts of $\mathrm{QA}$ were increased in rats fed the $+1 \%$ Trp diet group; however, there were no differences among the Trp diet groups.

Although the excretion amounts of SUM (Nam and its catabolites such as MNA, 2-Py, and 4-Py) were also increased in a dose-dependent manner, its content was at the same level in the $+2 \%$ and $+3 \%$ Trp diet groups and its content was decreased in the $+5 \%$ Trp diet group. The urinary excretion ratio of $(2-\mathrm{Py}+4-\mathrm{Py}) /$ MNA decreased with increasing dietary Trp levels. And the conversion percentage of Trp-Nam decreased with increasing dietary Trp levels.

\section{DISCUSSION}

In this study, we first clarified that a high dose of Trp prior to the development of type 2 diabetes did not suppress blood glucose concentrations. Some other reports $(10,25)$ have not been consistent with our results. Hundley et al. (25) reported that administration of Trp via stomach tube increased the blood glucose concentration in fasting alloxan-induced type 1 diabetic rats. Meanwhile, Inubushi et al. (10) demonstrated that a Trp-rich diet $(0.32 \%$ Trp diet) suppressed the elevation of blood glucose in type 2 diabetic Torii rats. The difference between these two experiments could be due to differences in study design. In the former study, Trp was administered after the development of diabetes (25), while in the latter study, the Trp-rich diet was provided prior to the development of diabetes (10). Furthermore, an oral dose of Trp was more effective than intraperitoneal injection with regard to the control of blood glucose (10).

In the present study, the oral administration of Trp did not suppress the elevation of blood glucose concentrations, despite administering Trp prior to the development

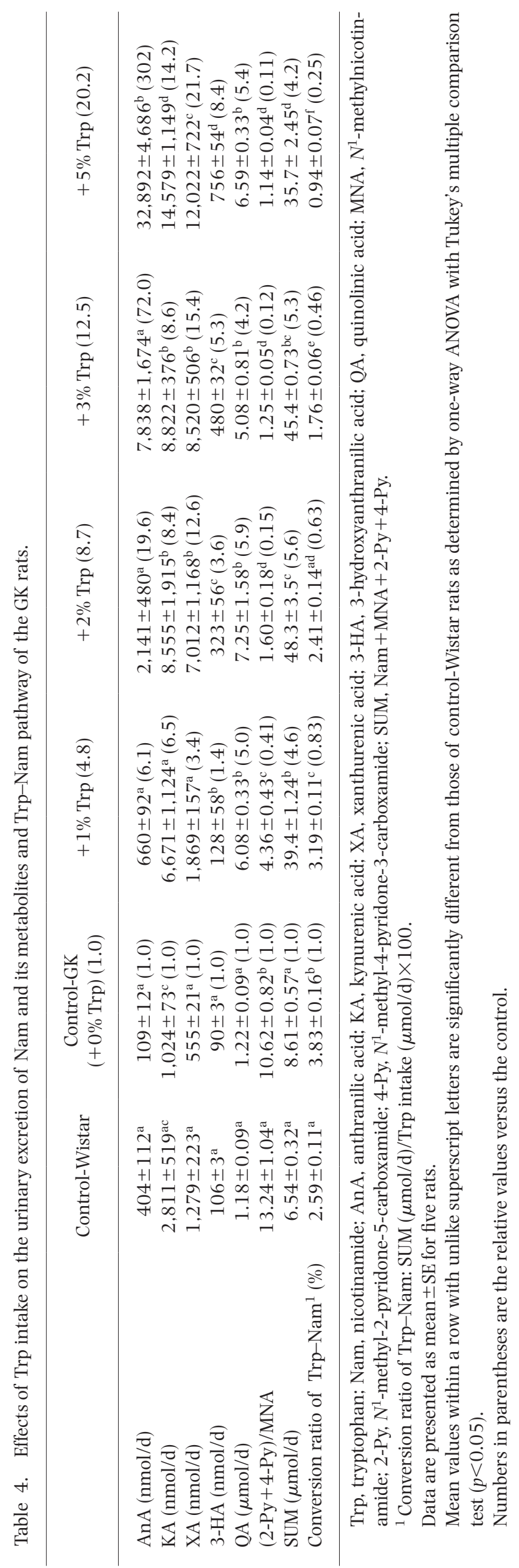



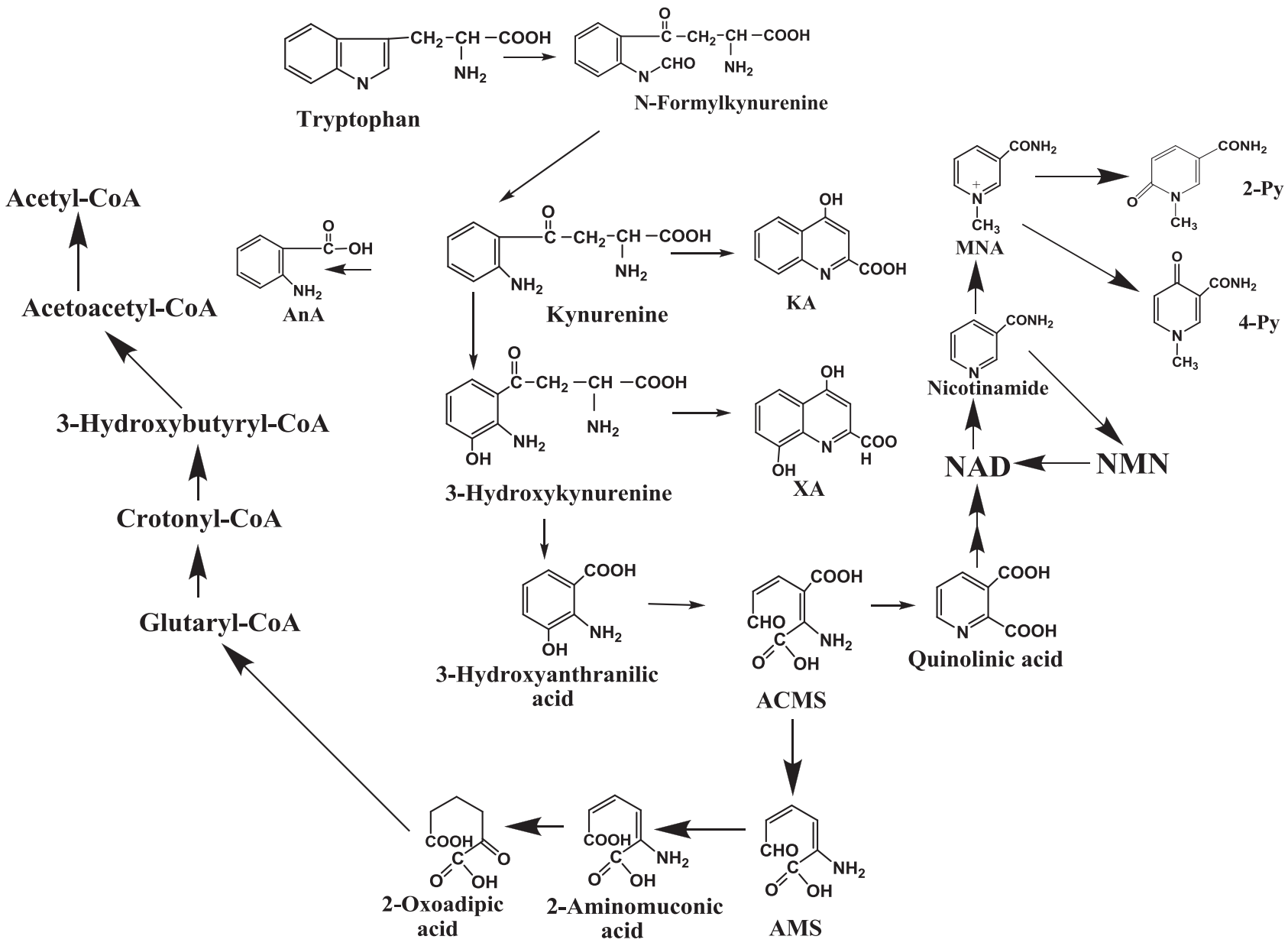

Fig. 2. Trp metabolism. ACMS, aminocarboxymuconate-semialdehyde; AMS, aminomuconate-semialdehyde; AnA, anthranilic acid; KA, kynurenic acid; NMN, nicotinamide mononucleotide; MNA, $N^{1}$-methylnicotinamide; 2-Py, $N^{1}$-methyl-2-pyridone-5-carboxamide; 4-Py, $N^{1}$-methyl-4-pyridone-3-carboxamide; XA, xanthurenic acid.

of type 2 diabetes. However, in comparisons between the OGTT administration days and between Trp addition amounts, the interaction effects were essentially not observed. The reduced pancreatic $\beta$-cell mass (26) and elevated basal plasma glucose (18) were detected in GK rats as young as 1 mo post-weaning. These symptoms are seen earlier than in Torii rats (27). It might be that Trp-rich chow consumed from a young age preserved the secretion of insulin and delayed the progression of type 2 diabetes. Together, the above results and our findings suggest that high-dose oral Trp is not useful in delaying the progression of mild hyperglycemia.

The reduction in food intake and the delay in body weight gain of the GK rats fed $+3 \%$ Trp and $+5 \%$ Trp diets were small compared with those of the GK rats fed the control diet. Therefore, the adverse effects of excessive intake of Trp were very weak in GK rats.

In addition, we revealed the Trp metabolism in GK rats. Figure 2 shows the Trp metabolism. We found that Nam is synthesized from Trp even in GK rats. Generally speaking, the synthesized amount of Nam is dependent on intake of Trp when it is within physiological amounts (28). In the present experiment, the conversion of Trp to Nam was maximized with the $+1 \%$ Trp diet. The same phenomenon was observed in the urinary excretion of QA. This finding observed in GK rats was a similar phenomenon to that seen in normal healthy animals (27). An abnormal increase in the urinary excretion of AnA in GK rats fed the $+5 \%$ Trp diet was also reported in normal healthy animals (27). This phenomenon is attributed to the properties of kynureninase (a pyridoxal phosphate-dependent enzyme) (29). The $K_{\mathrm{m}}$ value of kynurenine with kynureninase is much higher than that of 3-hydroxykynurenine (29), so the reaction of kynurenine $\rightarrow$ AnA occurs very little under normal Trp intake conditions. Meanwhile, with high Trp intake, the accumulation of kynurenine occurs, so the reaction of kynurenine $\rightarrow$ AnA occurs. Under physiological conditions, kynurenine is metabolized to 3-hydroxykynurenine, which is then hydrolyzed to 3-HA by kynureninase. 3-HA is metabolized to aminocarboxymuconatesemialdehyde, which then spontaneously cyclizes to form QA. The formation of QA increased 5-fold with the $+1 \%$ Trp diet compared with the control diet $(0.26 \%$ Trp diet), which was almost the same as the increase in Trp intake, and it did not increase with the higher Trp diets. These results indicate that the enzyme 3-HA 3,4-dioxygenase (a heme-containing enzyme) (30) that catalyzes the reaction 3 -HA $\rightarrow$ aminocarboxymuconatesemialdehyde is optimized owing to the $+1 \%$ Trp diet. 
3-HA 3,4-dioxygenase requires $\mathrm{Fe}^{2+}$; $\mathrm{QA}$ binds $\mathrm{Fe}^{2+}$ (31). Therefore, the increased QA from the Trp-rich diet might inhibit the activity of 3-HA 3,4-dioxygenase. We previously revealed that the formation of Nam from Trp is subject to the QA formation, and the enzyme that governs it is 3-HA 3,4-dioxygenase (32). Therefore, these findings indicate that the same mechanism exists in GK rats as in normal healthy animals.

The Trp catabolites KA and XA are side intermediates. KA spontaneously forms from 4-(2-aminophenyl)2,4-dioxobutanoic acid and glutamic acid from kynurenine and 2-oxoglutaric acid by kynurenine aminotransferase (a pyridoxal phosphate-dependent enzyme). XA spontaneously forms from 4-(2-amino3-hydroxyphenyl)-2,4-dioxobutanoic acid and glutamic acid from 3-hydroxykynurenine and 2-oxoglutaric acid by the same enzyme, kynurenine aminotransferase. The urinary excretion amounts of these two side metabolites $\mathrm{KA}$ and XA were mildly increased with the increase in Trp intake. Thus, the activity of kynurenine aminotransferase could be strong enough to metabolize a large amount of Trp.

In the present experiment using GK rats, the urinary excretion ratio (2-Py +4-Py)/MNA decreased with Trprich diets as well as in normal healthy animals (27). This phenomenon is due to the inactivation of 4-Py-forming MNA oxidase being suppressed by the substrate MNA (33). A Trp-rich diet causes MNA formation to increase, and the accumulated MNA inactivates 4-Py-forming MNA oxidase (33).

We found in the present study that the high doses of Trp prior to the development of type 2 diabetes did not suppress blood glucose levels. The metabolic response was found to be nearly the same in normal healthy animals and GK rats. We previously reported on the metabolism of Trp in healthy humans $(34,35)$. The pathophysiological relevance of Trp metabolism in type 2 diabetes should be examined in humans.

\section{Acknowledgments}

This investigation was part of the project "Studies on the nutritional evaluation of amino acids and B-group vitamins" (principal investigator, Katsumi Shibata), which was supported by a Grant-in-Aid for Scientific Research from the Japan Society for the Promotion of Sciences (grant number 24300258).

\section{Author contributions}

E.I. and K.S. designed the study. E.I. conducted the experiments. E.I. drafted the manuscript, and K.S. revised and reviewed the manuscript. All authors read and approved the final manuscript.

\section{REFERENCES}

1) Wurtman RJ. 1982. Nutrients that modify brain function. Sci Am 246: 50-59.

2) Cardinali DP. 1981. Melatonin. A mammalian pineal hormone. Endocr Rev 2: 327-346.

3) Fernstrom JD. 2000. Can nutrient supplements modify brain function? Am J Clin Nutr 71: 1669S-1675S.
4) Chen T, Zheng X, Ma X, Bao Y, Ni Y, Hu C, Rajani C, Huang F, Zhao A, Jia W, Jia W. 2016. Tryptophan predicts the risk for future type 2 diabetes. PLoS One 11: e0162192.

5) MacKenzie RG, Trulson ME. 1978. Does insulin act directly on the brain to increase tryptophan levels? J Neurochem 30: 1205-1208.

6) Herrera R, Manjarrez G, Nishimura E, Hernandez J. 2003. Serotonin-related tryptophan in children with insulin-dependent diabetes. Pediatr Neurol 28: 20-23.

7) Yokoi N, Beppu M, Yoshida E, Hoshikawa R, Hidaka S, Matsubara T, Shinohara M, Irino Y, Hatano N, Seino S. 2015. Identification of putative biomarkers for prediabetes by metabolome analysis of rat models of type 2 diabetes. Metabolomics 11: 1277-1286.

8) Wittman JS 3rd. 1976. Alteration of glucose tolerance by dietary L-tryptophan in rats. J Nutr 106: 631-635.

9) Tormo MA, Romero de Tejada A, Morales I, Paredes S, Sanchez S, Barriga C, Hernandez R. 2004. Orally administered tryptophan and experimental type 2 diabetes. Mol Cell Biochem 261: 57-61.

10) Inubushi $\mathrm{T}$, Kamemura N, Oda M, Sakurai J, Nakaya Y, Harada N, Suenaga M, Matsunaga Y, Ishidoh K, Katunuma N. 2012. L-tryptophan suppresses rise in blood glucose and preserves insulin secretion in type-2 diabetes mellitus rats. J Nutr Sci Vitaminol 58: 415-422.

11) Imai E, Sano M, Fukuwatari T, Shibata K. 2011. Tryptophan-nicotinamide metabolism in rats with streptozotocin-induced diabetes: association of dietary vitamin content. Nippon Eiyo Shokuryo Gakkaishi (J Jpn Soc Nutr Food Sci) 64: 313-321.

12) Shibata K. 1987. Tryptophan-niacin metabolism in alloxan diabetic rats and partial prevention of alloxan diabetes by nicotinamide. Agric Biol Chem 51: 811-816.

13) Pullman ME, Colowick SP. 1954. Preparation of 2- and 6-pyridones of N1-methylnicotinamide. J Biol Chem 206: $121-127$.

14) Shibata K, Kawada T, Iwai K. 1987. High-performance liquid chromatographic determination of nicotinamide in rat tissue samples and blood after extraction with diethyl ether. J Chromatogr 422: 257-262.

15) Reeves PG. 1997. Components of the AIN-93 diets as improvements in the AIN-76A diet. J Nutr 127: 838S-841S.

16) Goto Y, Kakizaki M, Masaki N. 1975. Spontaneous-diabetes produced by selective breeding of normal Wistar rats. Proc Jpn Acad 51: 80-85.

17) Ostenson CG, Khan A, Abdel-Halim SM, Guenifi A, Suzuki K, Goto Y, Efendic S. 1993. Abnormal insulin secretion and glucose metabolism in pancreatic islets from the spontaneously diabetic GK rat. Diabetologia 36: 3-8.

18) Portha B, Serradas P, Bailbe D, Suzuki K, Goto Y, Giroix MH. 1991. Beta-cell insensitivity to glucose in the GK rat, a spontaneous nonobese model for type II diabetes. Diabetes 40: 486-491.

19) Shibata K, Kawada T, Iwai K. 1988. Simultaneous micro-determination of nicotinamide and its major metabolites, $N^{1}$-methyl-2-pyridone-5-carboxamide and $N^{1}$-methyl-4-pyridone-3-carboxamide, by high-performance liquid chromatography. J Chromatogr 424: 23-28.

20) Shibata K. 1987. Ultramicro-determination of $N^{1}$-methylnicotinamide in urine by high-performance liquid chromatography. Vitamins 61: 599-604. 
21) Shibata K, Onodera M. 1992. Simultaneous high-performance liquid chromatographic measurement of xanthurenic acid and 3-hydroxyanthranilic acid in urine. Biosci Biotechnol Biochem 56: 974.

22) Shibata K. 1988. Fluorimetric micro-determination of kynurenic acid, an endogenous blocker of neurotoxicity, by high-performance liquid chromatography. J Chromatogr 430: 376-380.

23) Mawatari K, Oshida K, Iinuma F, Watanabe M. 1996. Determination of quinolinic acid by liquid chromatography with fluorimetric detection. Adv Exp Med Biol 398: 697-701.

24) Slot C. 1965. Plasma creatinine determination. A new and specific Jaffe reaction method. Scand J Clin Lab Invest 17: 381-387.

25) Hundley JM, McDaniel EG, Sebrell WH. 1956. Tryptophan-niacin metabolism in alloxan diabetic rats. J Nutr 59: 407-423.

26) Movassat J, Saulnier C, Portha B. 1995. Beta-cell mass depletion precedes the onset of hyperglycaemia in the GK rat, a genetic model of non-insulin-dependent diabetes mellitus. Diabete Metab 21: 365-370.

27) Shinohara M, Masuyama T, Shoda T, Takahashi T, Katsuda Y, Komeda K, Kuroki M, Kakehashi A, Kanazawa Y. 2000. A new spontaneously diabetic non-obese Torii rat strain with severe ocular complications. Int J Exp Diabetes Res 1: 89-100.

28) Shibata K, Matsuo H. 1990. Effect of dietary tryptophan levels on the urinary excretion of nicotinamide and its metabolites in rats fed a niacin-free diet or a constant total protein level. J Nutr 120: 1191-1197.

29) De Antoni A, Costa C, Allegri G. 1975. Studies on 3-hydroxykynureninase from rat liver. Acta Vitaminol Enzymol 29: 339-343.

30) Okuno E, Kohler C, Schwarcz R. 1987. Rat 3-hydroxyanthranilic acid oxygenase: purification from the liver and immunocytochemical localization in the brain. $J$ Neurochem 49: 771-780.

31) Muller AC, Dairam A, Limson JL, Daya S. 2007. Mechanisms by which acyclovir reduces the oxidative neurotoxicity and biosynthesis of quinolinic acid. Life Sci 80: 918-925.

32) Shibata K, Morita N, Shibata Y, Fukuwatari T. 2013. Enzymes that control the conversion of L-tryptophannicotinamide and the urinary excretion ratio $\left(N^{1}-\right.$ methyl-2-pyridone-5-carboxamide $+N^{1}$-methyl-4-pyridone-3-carboxamide) $/ \mathrm{N}^{1}$-methylnicotinamide in mice. Biosci Biotechnol Biochem 77: 2105-2111.

33) Shibata K, Matsuo H. 1989. Inhibition of $N^{1}$-methylnicotinamide oxidase activity by a large amount of $N^{1}$-methylnicotinamide injected into rats. Agric Biol Chem 53: 2393-2397.

34) Hiratsuka C, Fukuwatari T, Sano M, Saito K, Sasaki S, Shibata K. 2013. Supplementing healthy women with up to $5.0 \mathrm{~g} / \mathrm{d}$ of L-tryptophan has no adverse effects. J Nutr 143: 859-866.

35) Hiratsuka C, Fukuwatari T, Shibata K. 2012. Fate of dietary tryptophan in young Japanese women. Int $J$ Tryptophan Res 5: 33-47. 